\title{
Avaliação de um método para estimar a absorção radicular do nitrato em arroz
}

O nitrogênio é absorvido pelas raízes das plantas na forma de nitrato (NO3-) e de amônio ( $(\mathrm{NH4+)}$. Sob condições de alagamento, há maior disponibilização do nitrogênio na forma amoniacal, podendo ocorrer toxidez pelo excesso desse íon nas plantas. $\mathrm{O}$ arroz, entretanto, dada sua alta capacidade de transportar oxigênio da parte aérea para o sistema radicular através dos aerênquimas, é capaz de criar uma condição de nitrificação na rizosfera, possibilitando o equilibrio entre essas duas formas e evitando, assim, a toxidez por excesso de amônio. Nos estudos de avaliação da cinética de absorção do nitrogênio em arroz e em outras espécies, o método mais empregado é o da avaliação da redução em sua concentração na solução nutritiva no tempo. Contudo, esse método apresenta um problema de natureza fisiológica, um de natureza estatística e outro que é um erro de natureza procedimental que normalmente se comete. Do
ponto de vista fisiológico, o problema que se apresenta é que, na raiz, os transportadores do nitrogênio ficam sujeitos não só a um tratamento, mas a todas as diferentes concentrações desse elemento, o que pode vir a afetar sua afinidade e consequentemente o seu funcionamento. Em termos estatísticos, as avaliações sucessivas na mesma unidade experimental levam à autocorrelação dos resíduos, o que contraria a independência requerida deles para possibilitar o ajuste de modelos de regressão. 0 erro procedimental que se comete e, na maioria das vezes não se deixa explícito, é o de não se realizar a reposição do volume de amostra extraída da solução com água quimicamente pura. Considerando esses aspectos, e observando que não há relatos na literatura acerca de outros métodos alternativos nessa mesma linha de avaliação, propõe-se, com este trabalho, avaliar um método de cinética da absorção do nitrato em arroz baseado na exposição de plantas de arroz a apenas um único tratamento de concentração do íon, avaliando-se o seu teor no sistema radicular após um determinado período de tempo de exposição. Com isso, seriam evitados todos os problemas já mencionados. Para determinação dos teores de NO3-, foi realizado um estudo de caso empregando o método Kjeldahl. O método proposto neste trabalho não produziu resultados satisfatórios, porém especificamente devido à limitação do método de Kjeldahl, cuja resolução (limite de detecção) impossibilita identificar valores da magnitude daqueles encontrados na cinética de absorção do nitrato em arroz. Sugere-se que o método proposto seja revalidado empregando-se outro método de detecção do teor de $\mathrm{N}$ total ou especificamente NO3- nas raízes dessas plantas, porém com a resolução requerida.

Palavras-chave: Nitrogênio; Oryza sativa; Solução nutritiva.

\section{Evaluation of a method to estimate radicular absorption of nitrate in rice}

Nitrogen is absorbed by the roots of plants in the form of nitrate (NO3-) and ammonium (NH4+). Under flooding conditions, there is greater availability of nitrogen in ammoniacal form, and toxicity can occur due to the excess of this ion in plants. Rice, however, given its high capacity to transport oxygen from the aerial part to the root system through aerenchyma, is able to create a condition of nitrification in the rhizosphere, allowing the balance between these two forms and thus avoiding excess toxicity of ammonium. In studies evaluating the kinetics of nitrogen absorption in rice and other species, the most used method is that of assessing the reduction in its concentration in the nutrient solution over time. However, this method presents a problem of a physiological nature, one of a statistical nature and another that is a procedural error that is usually made. From a physiological point of view, the problem that arises is that, at the root, nitrogen transporters are subject not only to a treatment, but to all the different concentrations of this element, which may affect its affinity and consequently its operation. In statistical terms, the successive evaluations in the same experimental unit lead to the autocorrelation of the residues, which goes against the independence required of them to enable the adjustment of resrion models. The procedural error that is made and, in most cases, is not made explicit, is that of not replacing the volume of sample extracted from the solution with ature about other alternative methods in this same line of ev in the exposure of rice plants to only a single ion concentration treatment, evaluating its content in the roo system after a certain period of exposure. With that, all the problems already mentioned would be avoided. For the determination of NO3- levels, a case study was carried out using the Kjeldahl method. The method proposed in this work did not produce satisfactory results, but specifically due to the limitation of the Kjeldahl method, whose resolution (detection limit) makes it impossible to identify values in the magnitude of those found in the nitrate absorption kinetics in rice. It is suggested that the proposed method be reevaluated using another method of detecting the total $\mathrm{N}$ content or specifically the NO3- in the roots of these plants, however, with the required resolution.

Keywords: Nitrogen; Oryza sativa; Nutritive solution.

Topic: Ciências do Solo

Reviewed anonymously in the process of blind peer.

Bruna Regina Blanger (iD)

Universidade Federal de Mato Grosso, Brasil

http://lattes.cnpq.br/3707929624622672

http://orcid.org/0000-0001-9228-2647

brunaregina_blanger@hotmail.com

Francisco de Almeida Lobo (iD)

Universidade Federal de Mato Grosso, Brasil

http://lattes.cnpq.br/0296723198831816

http://orcid.org/0000-0002-5670-0351

fdealobo@gmail.com

Glaucio da Cruz Genuncio iD

Universidade Federal de Mato Grosso, Brasil

http://lattes.cnpq.br/6053030157161952

http://orcid.org/0000-0002-2884-688X

glauciogenuncio@gmail.com

a

DOI: $10.6008 / C B P C 2179-6858.2021 .006 .0001$
Received: 08/06/2021

Approved: 24/06/2021

Ana Cássia Silva Possamai id

Universidade Federal de Mato Grosso, Brasi

http://lattes.cnpq.br/7037110107076402

http://orcid.org/0000-0002-8785-8362

anacassiapossamai@unemt.br

Referencing this:

BLANGER, B. R.; LOBO, F. A.; GENUNCIO, G. C.; POSSAMAI, A. C. S.. Avaliação de um método para estimar a absorção radicular do nitrato em arroz. Revista Ibero Americana de Ciências Ambientais, v.12, n.6 p.1-19, 2021. DOI: http://doi.org/10.6008/CBPC21796858.2021.006.0001 


\section{INTRODUÇÃO}

A cultura do arroz tem relação direta com a sua importância alimentar e nutricional para mais da metade da população mundial, além de ser integrante do hábito alimentar da nossa população, possui grande valor energético (YOSHIDA, 1981; COUNCE et al., 2000).

Nos últimos anos os ganhos de rendimento na cultura diminuíram e a população mundial está aumentando em proporção maior do que os incrementos na produção do arroz, especialmente nos países consumidores do grão. Há poucas expectativas de expansão de áreas para cultivo, por isso o aumento do rendimento do arroz é necessário para atender à crescente demanda pelo grão (KHUSH, 1995).

É preciso, portanto, buscar progressos no tipo de planta e/ou manejo da lavoura do arroz para voltar a obter ganhos mais significativos no rendimento. Com relação à nutrição do arroz, aumentos de rendimento podem ser obtidos pelo manejo adequado da adubação (doses, épocas de aplicação, etc.) e/ou pelo desenvolvimento de genótipos mais eficientes na absorção e utilização de nutrientes (ABICHEQUER, 2004).

Quando se objetiva alcançar rendimentos de grãos mais altos em lavouras de arroz alagado, um dos aspectos a ser procurado é o aumento da absorção de nutrientes, para satisfazer a maior demanda que será criada. Também é necessário que se busque o aumento da eficiência na utilização de nutrientes pelas plantas (ABICHEQUER, 2004).

Além dos atributos morfológicos, a eficiência de absorção de nutrientes é influenciada pelos parâmetros cinéticos que compreendem a velocidade máxima de absorção (Vmax), a afinidade dos carregadores pelo íon a ser transportado (constante de Michaelis-Menten, Km) e a concentração na solução nutritiva junto às raízes onde o influxo para de ocorrer ( $\mathrm{Cmin}$ ) (HORN et al., 2006).

Plantas de arroz mais eficientes na absorção de nutrientes podem também reduzir perdas de nutrientes por percolação, volatilização (no caso do N) ou com a água de drenagem, ao absorvê-los em maior quantidade e mais rapidamente. Consequentemente, há melhor aproveitamento da adubação (ABICHEQUER, 2004).

O nitrogênio se apresenta como o nutriente mais importante para o arroz, devido ao elevado requerimento desse macronutriente pelas plantas e devido ao seu elevado custo como fertilizante. Assim sendo, torna-se crucial identificar materiais de arroz com maior eficiência na absorção e no uso desse nutriente (SANTOS, 2006) e explorar a capacidade dos transportadores de nutrientes nas células das raízes (FORDE, 2002; SUENAGA et al., 2003; Ll et al., 2009).

Consultando os trabalhos desenvolvidos para avaliação da absorção do nitrogênio em arroz nas bases de dados como Scientific Electronic Library Online (SciELO), do Web of Science, do Scopus e do portal da Capes, observa-se que dos artigos publicados do tema, em grande parte deles se emprega o método da avaliação da redução do teor de nitrogênio da solução nutritiva no tempo.

Contudo, é preciso ter a consciência de que esse método apresenta problemas. Do ponto de vista fisiológico, o problema que se apresenta é que, na raiz, os transportadores do nitrogênio ficam sujeitos não só a um tratamento, mas a todas as diferentes concentrações desse elemento, o que pode vir a afetar sua 
afinidade e consequentemente o seu funcionamento. Em termos estatísticos, as avaliações sucessivas na mesma unidade experimental levam à autocorrelação dos resíduos, o que contraria a independência requerida deles para possibilitar o ajuste de modelos de regressão. $O$ erro procedimental que se comete e, na maioria das vezes não se deixa explícito, é o de não se realizar a reposição do volume de amostra extraída da solução com água quimicamente pura.

A busca por plantas agronomicamente mais competentes requer, como ponto de partida, ampla diversidade genética. Desafortunadamente, a base genética dos cultivos comerciais em quase todo o mundo é estreita e isso ocorre com o arroz. Assim, as variedades não comerciais (variedades caboclas) de arroz são materiais de grande importância para o melhoramento genético (ABADIE et al., 2005).

Em São Pedro de Joselândia, uma comunidade rural situada em Barão de Melgaço no Pantanal MatoGrossense, se cultivam alguns materiais vegetais não comerciais, dentre eles duas variedades caboclas de arroz, localmente denominados de Branquinho e Agulhinha Vermelho.

Considerando a importância do arroz como alimento, a necessidade de ampliar a base genética para fins de melhoramento de planta, o nitrogênio como macronutriente fundamental desse cultivo e os problemas metodológicos para avaliação da cinética de absorção do nitrogênio, realizou-se este trabalho de pesquisa com o objetivo de testar um método inédito na avaliação da absorção do nitrato em uma variedade cabocla de arroz proveniente do Pantanal Mato-Grossense.

\section{REVISÃO TEÓRICA}

\section{Exigência Nutricional}

A exigência nutricional do arroz é determinada por vários fatores, tais como, condições climáticas, tipo de solo, cultivar, produtividade esperada e práticas culturais adotadas. O acúmulo de nutrientes pela cultura do arroz de terras altas em solo de Cerrados, obedece à seguinte ordem: $\mathrm{N}>\mathrm{K}>\mathrm{P}>\mathrm{Ca}>\mathrm{Mg}>\mathrm{Fe}>$ $\mathrm{Mn}>\mathrm{Zn}>\mathrm{Cu}$. Na cultura do arroz irrigado, o acúmulo de nutrientes ocorre na seguinte ordem: $\mathrm{K} \geq \mathrm{N}>\mathrm{P}>$ $\mathrm{Mg} \geq \mathrm{Ca}>\mathrm{Mn}>\mathrm{Fe}>\mathrm{Zn}>\mathrm{Cu}>\mathrm{B}$ (EMBRAPA, 2006).

Estudos realizados comprovam a importância do arroz quanto à eficácia na aquisição e uso do $\mathrm{N}$ graças aos genes envolvidos na melhoria no uso eficiente de nitrogênio, diminuindo consideravelmente o uso dos fertilizantes químicos que resultam em poluição ao meio ambiente, mudanças climáticas e perda da biodiversidade (BREDEMEIER et al., 2000; Ll et al., 2017).

A sustentabilidade da agricultura mundial é dependente da seleção de variedades que promovam um melhor mecanismo na absorção do nitrogênio em solos de baixas concentrações, por isso é necessário um entendimento profundo das respostas moleculares e fisiológicas de plantas submetidas a baixas concentrações de nitrogênio (GLASS et al., 2002).

Segundo Souza et al. (1995) variedades locais de arroz do estado do Maranhão são mais eficientes no uso do $\mathrm{N}$ acumulado e, portanto, menos dependentes de suplementação externa desse nutriente que variedades melhoradas. Essas variedades de arroz apresentam diferentes respostas ao nitrogênio em termos 
de acúmulo e redistribuição na matéria seca (SOUZA et al., 1998).

É importante considerar que variedades locais que apresentam maior eficiência no uso do nitrogênio, quando comparadas com variedades melhoradas, sugerem que o processo de melhoramento que vem sendo empregado em variedades de arroz tenha sido realizado em condições nutricionais que selecionaram variedades produtivas, porém mais exigentes em nitrogênio (SOUZA, 2010).

Na cultura de arroz, a importância do nitrogênio é indiscutível. Esse elemento é responsável pelo aumento dos componentes de produtividade (FAGERIA et al., 1997; FAGERIA et al., 1999), tais como o aumento da área foliar, o que aumenta a eficiência de intercepção da radiação solar e a taxa fotossintética e, consequentemente, a produção. É um dos elementos que mais limitam a produtividade do arroz irrigado em solos de várzea do Brasil (FAGERIA et al., 2001; FAGERIA et al., 2003).

As principais razões da deficiência deste nutriente são suas perdas por vários processos, baixas doses de aplicação e diminuição do teor de matéria orgânica devido aos sucessivos cultivos.

Segundo Greenland (1958) e Wetselaar (1961a; 1961b), o clima tropical, caracterizado por duas estações bem definidas (um período de chuvas e um período seco), ocasiona fluxos sazonais de nitrato no solo. $\mathrm{O}$ mesmo fenômeno parece ocorrer nas regiões do cerrado brasileiro, onde o acúmulo de $\mathrm{N}-\mathrm{NO}_{3}{ }^{-}$no solo ocorre somente em curto período de tempo na estação chuvosa (NARDOTO et al., 2003). Desta forma, o N está sujeito à lixiviação mais intensa durante a estação das chuvas, tornando-se disponível para as plantas apenas no início do período úmido, portanto, devendo ser absorvido rapidamente.

A eficiência no uso de nitrogênio (EUN) tem sido definida como o rendimento de grãos por unidade de $\mathrm{N}$ disponível no solo (LEA et al., 2006) e esta EUN pode ser dividida em dois processos: eficiência na absorção, que é a habilidade da planta em remover o $\mathrm{N}$ do solo normalmente presente nas formas de $\mathrm{NO}_{3}{ }^{-} \mathrm{e}$ $\mathrm{NH}_{4}{ }^{+}$; e eficiência na utilização, que é a habilidade da planta em transferir o $\mathrm{N}$ para o grão, onde predomina na forma de proteínas.

\section{Nitrogênio na planta}

$\mathrm{O}$ nitrogênio $(\mathrm{N})$ é o elemento mineral que as plantas requerem em maiores quantidades. Ele faz parte da composição de muitos componentes celulares vegetais, incluindo clorofila, aminoácidos, proteínas, enzimas, NADH, NADPH, ATP e ácidos nucleicos. Dessa forma a deficiência de N inibe o crescimento vegetal. Se persistir a deficiência, as espécies podem apresentar clorose (amarelecimentos das folhas) principalmente nas folhas mais velhas, próximas à base da planta. Com o avanço da deficiência as folhas tornam-se completamente amarelas e desprendem-se da planta (TAIZ et al., 2017)

O nitrogênio é um macronutriente, e pode estar presente na solução do solo como nitrato $\left(\mathrm{NO}_{3}{ }^{-}\right)$, amônia $\left(\mathrm{NH}_{3}\right)$ ou amônio $\left(\mathrm{NH}_{4}^{+}\right)$. As formas de nitrogênio absorvidas pelas plantas incluem as inorgânicas $\mathrm{NO}_{3}{ }^{-}$, o nitrito $\left(\mathrm{NO}_{2}{ }^{-}\right)$, o $\mathrm{NH}_{4}{ }^{+}$e as orgânicas como aminoácidos e a ureia [( $\left.\mathrm{NH}_{2}\right)_{2} \mathrm{CO}$ ] (MOKHELE et al., 2012).

$\mathrm{O}$ nitrato $\left(\mathrm{NO}_{3}{ }^{-}\right)$é considerado a principal fonte de $\mathrm{N}$ mineral para o crescimento de plantas em solos aerados. Existem evidências de pelo menos três sistemas diferentes de absorção do $\mathrm{NO}_{3}{ }^{-}$nas plantas, sendo que dois deles são de alta afinidade pelo $\mathrm{NO}_{3}{ }^{-}$e o terceiro de baixa afinidade. Um dos sistemas de alta 
afinidade é altamente induzido pelos níveis de $\mathrm{NO}_{3}{ }^{-}$externos, sendo denominado sistema transportador de alta afinidade induzido por nitrato (iHATS), ao passo que o outro é constitutivo (cHATS) e está igualmente presente em plantas que não foram previamente supridas com $\mathrm{NO}_{3}{ }^{-} . \mathrm{O}$ sistema de baixa afinidade (LATS) parece ser igualmente constitutivamente expresso, em situações em que os níveis de $\mathrm{NO}_{3}{ }^{-}$externos são maiores que 1,0 mM (FORDE, 2000).

A absorção de nitrato é um processo ativo, ou seja, ocorre contra um gradiente de potencial eletroquímico, e necessita da geração de um gradiente de próton através da membrana plasmática, portanto depende da atividade das bombas de próton (P-H+H -ATPase) dessas membranas (GLASS et al., 1992; FORDE, 2000).

Na maioria das plantas apenas uma porção do $\mathrm{NO}_{3}{ }^{-}$é assimilado na raiz, sendo que o restante é transportado através do xilema pela via transpiratória para ser assimilado na parte aérea. No caso de haver $\mathrm{NO}_{3}{ }^{-}$excedente, este pode ficar acumulado no vacúolo ou até mesmo ser eliminado por extrusão através da membrana plasmática (FORDE, 2000).

A primeira etapa do processo de assimilação do nitrato é a sua conversão a nitrito pela ação da enzima redutase do nitrato (NR), localizada no citoplasma (TISCHNER, 2000). Essa enzima é a principal porta de entrada de $\mathrm{N}$ no metabolismo vegetal. A reação de redução envolve a transferência de dois elétrons:

$$
\mathrm{NO}_{3}^{-}+\mathrm{NAD}(\mathrm{P}) \mathrm{H}+\mathrm{H}^{+} \rightarrow \mathrm{NO}_{2}^{-}+\mathrm{NAD}(\mathrm{P})^{+}+\mathrm{H}_{2} \mathrm{O}
$$

Onde $\mathrm{NAD}(\mathrm{P}) \mathrm{H}$ indica o NADH ou o NADPH. A forma mais comum da enzima redutase do nitrato utiliza somente o NADH como doador de elétrons; uma outra forma da enzima, encontrada principalmente em tecidos não clorofilados, como raízes, pode usar tanto o NADH quanto o NADPH (TAIZ et al., 2017).

Nas plantas superiores, a redutase do nitrato que é uma enzima do citosol, é formada por duas sbunidades idênticas (enzimas denominadas homodiméricas) com três grupos prostéticos de transferência de elétrons por subunidade: a flavina adenina dinucleotídeo (FAD), o Fe-heme e um molibdênio molibdopterina (Mo-MPT) (CAMPBELL, 1999).

A nitrato redutase é considerada uma enzima chave na regulação do metabolismo de nitrogênio por ser a primeira e principal porta de entrada de nitrogênio na planta (PURCINO et al., 1994).

A atividade catalítica da redutase do nitrato depende da disponibilidade dos substratos $N A D(P) H$ e nitrato no citoplasma celular, bem como dos níveis e do estado de ativação da enzima funcional (CAMPBELL, 1999). A disponibilidade de luz e de oxigênio são os fatores externos que determinam a rápida e reversível modulação da atividade da redutase do nitrato, ao passo que a deficiência de nitrato no solo tem pouco efeito no estado de ativação da enzima (KAISER et al., 2001).

$\mathrm{O} \mathrm{NO}_{2}^{-}$, produto da atividade da redutase do nitrato, é um íon altamente reativo e potencialmente tóxico. As células vegetais realizam o transporte rápido do nitrito gerado pela redução do nitrato do citosol para o interior dos cloroplastos nas folhas e dos plastídios nas raízes. Nessas organelas a enzima nitrito redutase reduz o nitrito a amônio, uma reação que envolve a transferência de seis elétrons de acordo com a seguinte reação geral: 


$$
\mathrm{NO}_{2}{ }^{-}+6 \mathrm{Fd}_{\text {red }}+8 \mathrm{H}^{+} \rightarrow \mathrm{NH}_{4}^{+}+6 \mathrm{Fd}_{\mathrm{ox}}+2 \mathrm{H}_{2} \mathrm{O}
$$

Onde o Fd representa a ferrodoxina e os símbolos subescritos red e ox significam forma reduzida e oxidade, respectivamente.

Os cloroplastos e os plastídeos possuem diferentes formas da enzima, mas ambas as formas possuem dois grupos prostéticos: um grupo ferro-enxofre $\left(\mathrm{Fe}_{4} \mathrm{~S}_{4}\right)$ e um grupo heme especializado. Esses grupos atuam em conjunto ligando-se ao nitrito e reduzindo-o diretamente a amônio.

O amônio é então convertido em aminoácidos pelas enzimas sintetase da glutamina (GS) e sintetase do glutamato (GOGAT), formando glutamina (GLN), glutamato (GLU) e outros aminoácidos e seu metabólitos (CRAWFORD, 1995). Essas enzimas se localizam no citosol e nos plastídeos das raízes ou nos cloroplastídeos (BECKER et al., 1993). A partir da Glutamina que é formada, o grupamento amino (- $\left.\mathrm{NH}_{2}\right)$ é transferido para a a-cetoglutarato, proveniente do Clico de Krebs, pela ação da segunda enzima Glutamato Sintetase, com energia fornecida pela ferrodoxina reduzida (Fd) na parte aérea ou NADH na raiz, formando duas moléculas de glutamato, uma irá regenerar o ciclo (via GS/GOGAT) e a outra pode ser usada nas reações biossintéticas (SOUZA et al., 2006).

\section{Método de Classen \& Barber para avaliar a cinética de absorção de íons pela planta}

Em grande parte dos casos a absorção de nutrientes pelas plantas refere-se à absorção de íons (FAGERIA, 1984). Muitos estudos vêm sendo feitos nessa área, para entender o mecanismo de absorção de nutrientes pelas raízes das plantas e, embora já tenha sido alcançado muito progresso, vários aspectos ainda não foram entendidos.

A capacidade da planta em absorver nitrogênio caracteriza um fator constituinte da sua eficiência no uso deste nutriente, o conhecimento prévio dos parâmetros cinéticos da absorção de $\mathrm{NO}_{3}{ }^{-} \mathrm{e} \mathrm{NH}_{4}{ }^{+}$é, portanto, muito importante para a continuidade dos estudos relacionados a eficiência no uso de nitrogênio (SOUZA, 2010).

Para a determinação dos parâmetros cinéticos da absorção de $\mathrm{NO}_{3}{ }^{-}$e $\mathrm{NH}_{4}{ }^{+}$pelas variedades de arroz é necessário a realização de inúmeros experimentos com cada umas das variedades em diferentes concentrações do nutriente e posteriormente análise de grandes quantidades de amostras das soluções nutritivas nas quais as plantas foram cultivadas. Com isso a caracterização da diversidade genética, pode possibilitar ganho de tempo na obtenção de resultados aceitáveis, possibilitando a seleção de variedades geneticamente mais distintas para a realização de experimentos, e impedindo a realização de experimentos com genótipos idênticos (SOUZA, 2010).

Epstein et al. (1952) introduziram um tratamento da cinética de absorção iônica em termos semelhantes à enzimologia. Eles propuseram uma cinética de absorção de íons semelhante à de MichaelisMenten (BARBER, 1984). De acordo com esta hipótese, a absorção de íons, em função da concentração externa, é simplesmente uma curva hiperbólica. A taxa de absorção de íons desta curva pode ser explicada, utilizando-se a Equação 1 da cinética de Michaelis-Menten (BARBER, 1984). 


$$
I=\frac{V_{\text {máx }}(C)}{K_{m}+C}
$$

Equação 1

Em que: $I=$ influxo, ou velocidade de absorção do íon, $V_{\text {máx }}=$ velocidade de absorção máxima do íon, $C=$ concentração do íon no meio externo, $K_{m}=$ constante de Michaelis-Menten para o transportador do íon.

Considerando que há um nível mínimo de $C$ para o qual o valor de I é nulo, a Equação 1 deve ser reescrita considerando esse aspecto, tomando o formato da Equação 2.

$$
I=\frac{V_{\operatorname{máx}}\left(C-C_{m i ́ n}\right)}{K_{m}+\left(C-C_{m i n}\right)}
$$

Em que: $I=$ influxo, ou velocidade de absorção do íon, $V_{\text {máx }}=$ velocidade de absorção máxima do íon, $C=$ concentração do íon no meio externo, $C_{\min }=$ concentração do íon no meio externo em que $I=0, K_{m}=$ constante de MichaelisMenten para o transportador do íon.

Classen et al. (1974) desenvolveram um método baseado na taxa de depleção do íon na solução nutritiva para estimar os valores de $V_{\text {máx }}, K_{m}$ e $C_{\text {minn. }}$. Este método consistia em se medir a concentração do elemento na solução nutritiva em uma séria de intervalos de tempo consecutivos e utilizar os dados para a construção de uma curva. Nesse caso, a diminuição no conteúdo de íons da solução é atribuída à absorção do íon pela planta (CLASSEN et al., 1974).

Com base no método de Classen et al. (1974) propôs um processo gráfico matemático para determinação dos parâmetros cinéticos e posteriormente (RUIZ et al., 1992) desenvolveram o software "Cinética Win", no qual dados obtidos em um experimento de cinética pelo método da depleção podem ser facilmente utilizados para gerar esses parâmetros.

A despeito dos inúmeros trabalhos já realizados em que o método da depleção é utilizado para avaliar a cinética do influxo de íons nas plantas, há alguns comprometimentos do mesmo que suscitam dúvidas acerca da qualidade dos resultados produzidos.

O método apresenta um problema de natureza fisiológica a ser mencionado. A exposição das plantas a alterações nas concentrações $\mathrm{NO}_{3}{ }^{-}$externos, decorrente das sucessivas amostragens realizadas na mesma solução nutritiva, pode afetar a atividade do próprio sistema iHATS, uma vez que estes, por sua natureza, são induzidos pelos níveis de $\mathrm{NO}_{3}{ }^{-}$externos. Além disso, há evidências que o sistema cHAT é, de alguma forma ainda não esclarecida, igualmente afetado pelos níveis de $\mathrm{NO}_{3}{ }^{-}$externos (ASLAM et al., 1992; KRONZUCKER et al., 1995; FORDE, 2000).

Assim, o próprio formato como o método de amostragem experimental é realizado pode produzir resultados que não necessariamente representam a forma como a absorção ocorreria se os tratamentos das diferentes concentrações de $\mathrm{NO}_{3}{ }^{-}$fossem aplicados em diferentes unidades experimentais. Por exemplo, quando da última amostragem, os transportadores já experimentaram toda a série de concentrações anteriores e não somente a última concentração.

Em outras palavras, as amostragens sucessivas na mesma unidade experimental só não afetariam o processo de absorção se, e somente se, todos os sistemas de influxo do $\mathrm{NO}_{3}{ }^{-}$das membranas citoplasmáticas fossem constitutivos e não afetados pelos níveis desse íon, o que não é uma verdade e por isso é possível levantar essa crítica ao método.

Um outro problema do método a ser mencionado é de natureza estatística. O ajuste de modelos 
matemáticos de regressão pelo método dos mínimos quadrados requer, como uma de suas suposições, a observância da independência dos resíduos. Medidas repetidas no tempo na mesma unidade experimental comprometem a independência dos resíduos porque, nesses casos, se verifica a existência de correlação entre eles (correlação direta ou com alguma defasagem), o que compromete seriamente o método dos mínimos quadrados para a estimativa dos parâmetros (SEBER et al., 2003).

O problema de natureza procedimental que igualmente se verifica é que há aqueles que não fazem a reposição das alíquotas amostradas com igual volume de água quimicamente pura à medida que estas vão sendo retiradas das unidades experimentais, em concordância com o método original proposto por Classen et al. (1974). Não é, portanto, um comprometimento do próprio método, mas sim um erro na condução do trabalho por parte de quem o executa, contudo ele existe. Só o fato dos pesquisadores não mencionarem o procedimento da reposição em seus trabalhos já levanta uma séria suspeita nesse sentido.

\section{Variedade estudada}

Nosso país dispõe de um banco de germoplasma de arroz usado para o melhoramento genético, que é constituído de espécies que foram perpetuadas em cultivos sucessivos nas comunidades rurais aos longos dos anos. Essas espécies evoluíram para variedades, hoje consideradas tradicionais e que contém o efeito de inúmeras variações genéticas ocorridas, principalmente pelas misturas de sementes, seguidas de cruzamento natural (MORAIS, et al., 2004).

As variedades locais são pouco cultivadas, persistindo apenas nas comunidades mais tradicionais. Há alguns anos, pesquisas vem sendo realizadas para desenvolver linhagens de arroz adaptadas ao Estado de Mato Grosso (EMBRAPA, 2008).

Sabe-se da existência de sementes de arroz caracterizados como não comerciais e que são cultivadas pelos moradores de São Pedro de Joselândia, distrito de Barão de Melgaço/MT, essas variedades tradicionalmente são cultivadas em áreas alagadas, anualmente, aproveitando a época de cheias da região, para subsistência das famílias. As variedades foram nomeadas localmente, como Branquinho e Agulhinha Vermelho ou somente Vermelhinho (OLIVEIRA, 2017).

Verificou-se que essas variedades são materiais particulares da região estudada, pertencente ao grupo japônica e os quais não se encontram na Coleção Nuclear de Arroz da Embrapa, é uma variedade de ciclo semi-tardio (137 dias) e foi observado um teor de proteína de 8,89\% (OLIVEIRA, 2017).

\section{MATERIAIS E MÉTODOS}

O experimento foi realizado em casa de vegetação da Faculdade de Agronomia e Zootecnia da Universidade Federal de Mato Grosso (UFMT) - Cuiabá/MT (latitude 15'36'31"S e longitude $56^{\circ} 03^{\prime} 48^{\prime \prime} \mathrm{W}$, e 176 metros de altitude). Foram determinados os parâmetros cinéticos de absorção de $\mathrm{N}$ de uma variedade de arroz não comercial que é cultivada pelos moradores de São Pedro de Joselândia, distrito de Barão de Melgaço/MT no pantanal Mato-Grossense (agulhinha vermelho, ou somente "vermelhinho").

O método proposto neste trabalho para avaliar a cinética de absorção de $\mathrm{NO}_{3}{ }^{-}$baseou-se na avaliação 
do teor de $\mathrm{N}$ total (Método Kjeldahl) presente nas raízes de plantas submetidas a diferentes concentrações do íon após um período de $72 \mathrm{~h}$ de supressão desse elemento químico na solução nutritiva. Além das concentrações estabelecidas, acrescentamos dois vasos em que a concentração de $\mathrm{N}$, foi igual a $0,0 \mathrm{mM}$, ou seja, as plantas ficaram somente em água destilada após o período de $72 \mathrm{~h}$, essa concentração de $0,0 \mathrm{mM}$ de nitrato produziu o "branco", e o N total presente nas raízes das outras plantas menos o presente nas raízes do "branco" foi tomado como sendo exclusivamente devido ao nitrato da solução.

Por questões pragmáticas, o experimento foi dividido em duas etapas: (a) soluções com concentrações dentro da faixa de ação dos transportadores de baixa afinidade e (b) soluções com concentrações dentro da faixa de ação dos transportadores de alta afinidade.

Empregou-se o delineamento em blocos ao acaso, com 11 tratamentos e quatro repetições para ambas as etapas do experimento. Cada parcela (vaso de 2,0L) foi composta por 3 plantas. Os tratamentos consistiam em 11 concentrações de $\mathrm{N}$ (variando de 2,0 a 0,2 mM e de 0,2 a 0,02 mM), conforme Tabela 1 abaixo.

Tabela 1: Concentrações de nitrato utilizadas no experimento conforme afinidade dos carregadores.

\begin{tabular}{ll}
\hline Baixa afinidade & Alta afinidade \\
$\mathbf{2 , 0} \mathbf{~ m M - 0 , 2 ~} \mathbf{~ M M}$ & $\mathbf{0 , 2} \mathbf{~} \mathbf{M}-\mathbf{0 , 0 2} \mathbf{~ m M}$ \\
\hline 2,0 & 0,20 \\
1,8 & 0,18 \\
1,6 & 0,16 \\
1,4 & 0,14 \\
1,2 & 0,12 \\
1,0 & 0,10 \\
0,8 & 0,08 \\
0,6 & 0,06 \\
0,4 & 0,04 \\
0,2 & 0,02 \\
0,0 & 0,00 \\
\hline
\end{tabular}

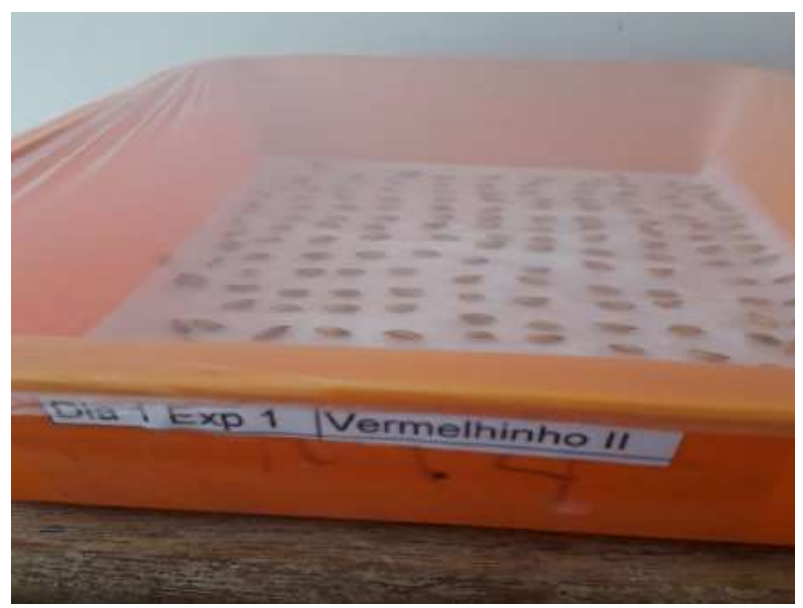

Figura 1: Sementes na bandeja para germinação.

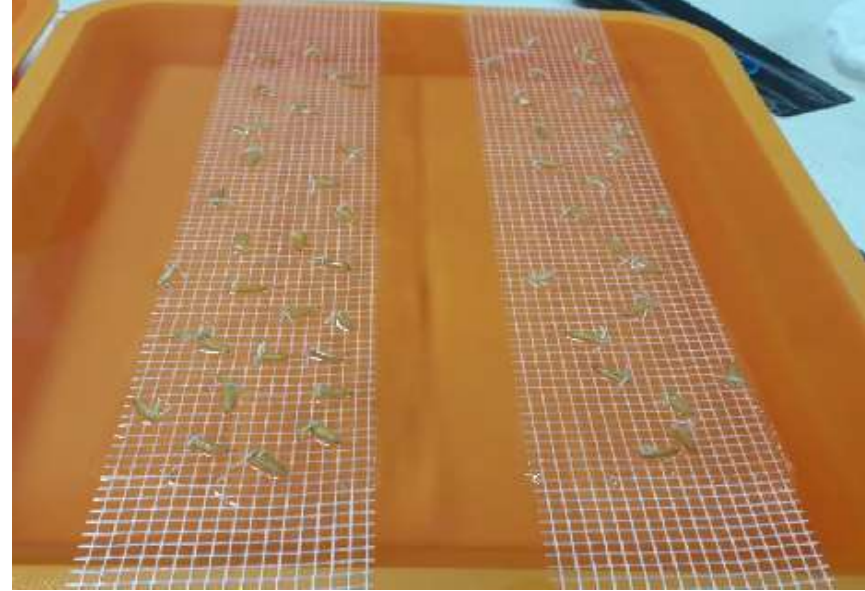

Figura 2: Plântulas sob tela na bandeja e raízes em contato com a solução nutritiva.

As sementes foram colocadas para germinar de forma escalonada, cada dia foram colocadas para germinar as sementes referentes de cada repetição, ou seja, cada dia uma repetição. Inicialmente as sementes foram previamente desinfetadas em solução de hipoclorito de sódio (2\%), durante 10 minutos e depois lavadas várias vezes com água destilada até eliminar qualquer resíduo restante de hipoclorito. Após 
o tratamento das sementes, estas foram colocadas para germinar em bandeja de plástico com papel de germinação no fundo e umedecido somente com água destilada e a bandeja coberta com plástico filme (Figura 1), durante 2 dias (prazo para emissão de radícula, conforme teste realizado previamente).

Depois disso, as plântulas foram mantidas sobre uma tela de plástico, e na bandeja foi adicionada a solução nutritiva de Hoagland et al. (1950) a 1/4 da força iônica, deixando somente as raízes ficarem em contato com a solução, para iniciar a adaptação com a solução nutritiva (Figura 2).

Para formulação das soluções nutritivas utilizadas no decorrer do experimento foram usados os seguintes fertilizantes com suas respectivas dosagens (Tabela 2).

Tabela 2: Fertilizantes utilizados na formulação da solução nutritiva e respectivas dosagens conforme força iônica da solução.

\begin{tabular}{llll}
\hline & & $\mathbf{g} / \mathbf{1 0 0 0 L}$ & $\mathbf{2 5 \%}$ \\
\hline Fertilizantes & $\mathbf{1 0 0 \%}$ & $\mathbf{5 0 \%}$ & 210,50 \\
\hline Calcinit & 842,00 & 421,00 & 125,00 \\
Krista K & 500,00 & 250,00 & 22,60 \\
Krista MKP & 90,40 & 45,20 & 9,88 \\
Krista MAG & 39,50 & 19,75 & 33,50 \\
Krista SOP & 134,00 & 67,00 & 13,25 \\
MgSO $_{4}$ & 53,00 & 26,50 & 112,50 \\
Krista MOP & 450,00 & 225,00 & 3,80 \\
ConMicros & 15,20 & 7,60 & \\
\hline
\end{tabular}

Três dias após esse processo de adaptação, as plantas similares ao desenvolvimento de parte aérea e raiz foram transferidas para vasos de plástico, pintados externamente com tinta spray cinza aluminizada com capacidade de 2,0 L, e dispostos sobre bancadas na casa de vegetação. Uma lâmina de isopor forrada com papel alumínio, com 3 furos equidistantes foi ajustada na parte superior interna de cada vaso e em cada furo foi colocada espuma com objetivo de manter as plantas eretas e apenas o sistema radicular ficou em contato com a solução (Figura 3).
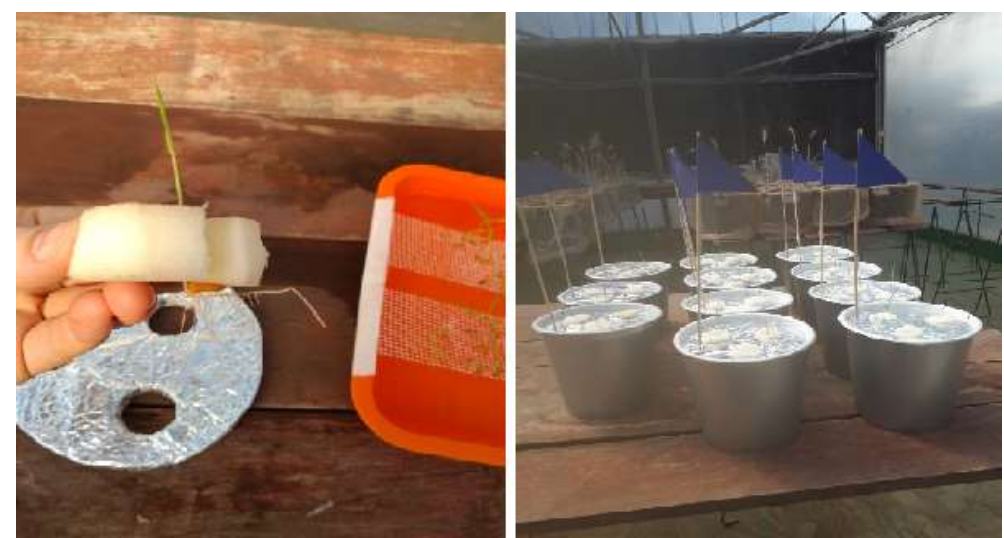

Figura 3: Plantas nos vasos na casa de vegetação.

Também neste segundo momento foi utilizada a solução de Hoagland et al. (1950) com 1/4 da força iônica, porém durante os 5 primeiros dias (plântulas nas bandejas). Quando as plantas foram transferidas para os vasos na casa de vegetação, utilizou-se também a solução com $1 \frac{1}{4}$ da força iônica, porém dois dias depois observou-se que as plantas estavam queimando, e houve a troca da solução, para 10\% da força iônica durante três dias (para realizar a aclimatação das plantas na casa de vegetação), posteriormente a solução foi novamente trocada para a $1 / 4$ da força iônica e as plantas permaneceram doze dias nessa solução. Em 
seguida a solução foi trocada para $1 / 2$ da força iônica durante nove dias e finalmente a solução foi trocada para $100 \%$ da força iônica nos últimos 4 dias do experimento.

Depois de 40 dias após a germinação (DAG) (estádio de desenvolvimento vegetativo V7-V8), as plantas foram privadas de $\mathrm{N}$ na solução nutritiva durante 72 horas, e a partir de então a solução foi reposta com as diferentes concentrações estabelecidas (Figura 4).

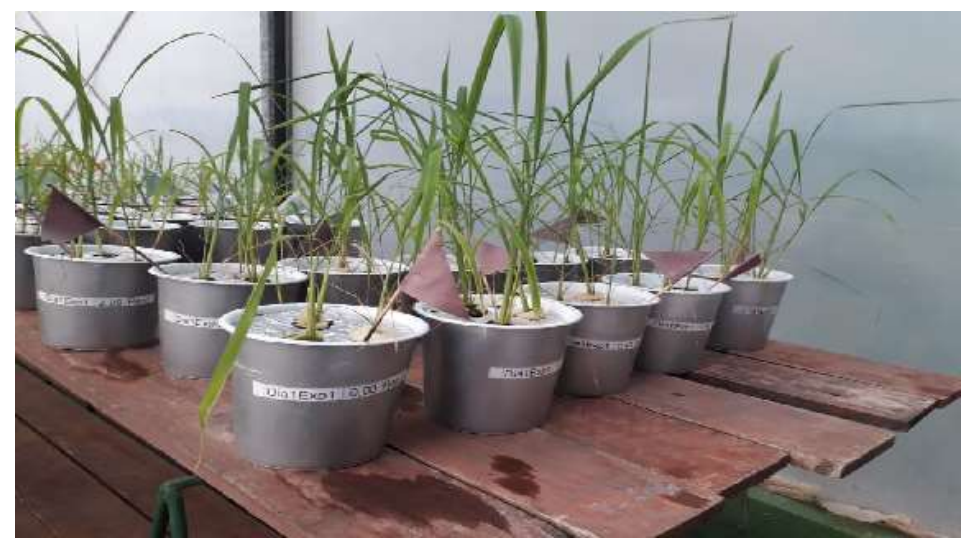

Figura 4: Plantas de arroz no dia da realização da cinética.

Neste momento, as soluções foram formuladas somente com N, utilizando-se o fertilizante Krista K (nitrato de potássio) da empresa Yara, e o pH mantido em 5,8. Após 30 minutos, as plantas foram retiradas da solução e as raízes separadas e imediatamente lavadas várias vezes em água destilada (Figura 5) e depois acondicionadas em sacos de papel para secar em estufa a $65^{\circ} \mathrm{C}$ durante três dias até massa constante. Depois de retirar as plantas, foram realizadas as medidas de $\mathrm{pH}$ e condutividade elétrica dos vasos.
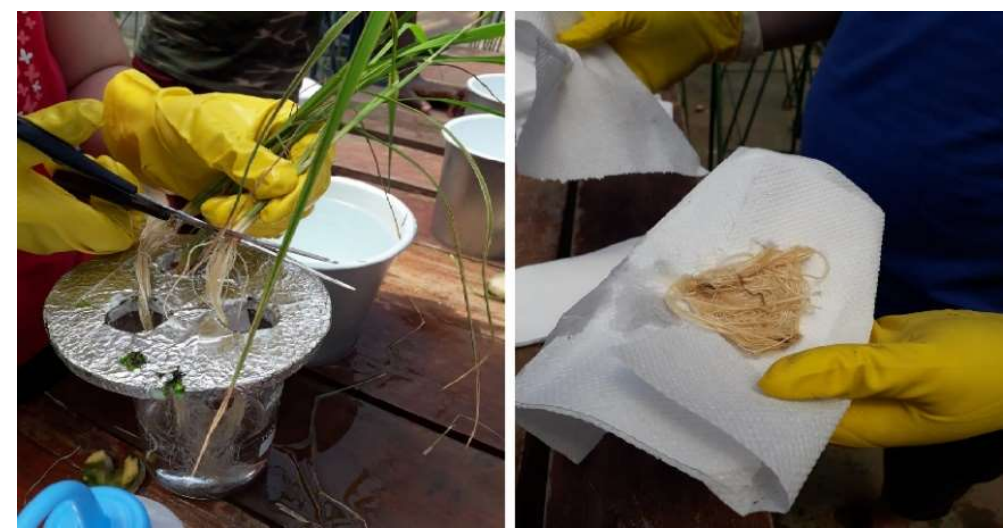

Figura 5: Raízes sendo separadas da planta, lavadas em água destilada e retirado o excesso de água para ir para os sacos de papel.

Após pesadas, as amostras foram colocadas em sacos de plástico, identificadas e enviadas para análise laboratorial para quantificação de N.

A solução nutritiva teve $\mathrm{pH}$ entre 5,8 e 6,1 , ajustadas com $\mathrm{HCL}$ ou $(\mathrm{KOH})$. O pH e a condutividade elétrica das soluções foram medidos diariamente, e estabeleceu-se que a solução seria trocada se o pH estivesse abaixo de 5,5 ou atingisse 6,5 . Ou se a condutividade variasse em $15 \%$ em relação ao dia que houve troca de solução.

Para todos os casos, o cálculo do influxo de $\mathrm{NO}_{3}^{-}$para as raízes das plantas foi calculado a partir dos 
resultados analíticos dos teores de $\mathrm{N}$ total de cada tratamento subtraído do teor de $\mathrm{N}$ total do branco $(0,0$ $\mathrm{mM}$ de $\mathrm{NO}_{3}^{-1}$ na solução nutritiva) e dividido pelo tempo de $0,5 \mathrm{~h}$ referente à permanência das plantas na solução com o tratamento especificado. Com isso, se teria apenas o $\mathrm{N}$ na forma de $\mathrm{NO}_{3}{ }^{-}$que foi absorvido nesse tempo, eliminando-se todas as demais formas de $\mathrm{N}$ já presentes em outros compostos estruturais e não estruturais na raiz. Como o teor de $\mathrm{N}$ total proveniente das análises do Laboratório de Análises de Plantas é dado em $\mathrm{g} \mathrm{kg}^{-1}$, sua conversão em mol $\mathrm{kg}^{-1}$ foi feita dividindo-se a massa de $\mathrm{N}$ dada em g pelo valor do seu mol $\left(14,0067 \mathrm{~g} \mathrm{~mol}^{-1}\right)$. Uma vez que cada mol de $\mathrm{NO}_{3}{ }^{-}$tem um mol de $\mathrm{N}$, essa conversão permitiu igualmente considerar o resultado do cálculo do influxo foi de $\mathrm{NO}_{3}$.

A partir desses cálculos de influxo de $\mathrm{NO}_{3}{ }^{-}$, seria realizado o ajuste da curva de cinética da absorção do íon de acordo com a Equação 2, a fim de estimar, em cada caso, os valores de $V_{\max }, K_{m}$ e $C_{\min }$. $O$ ajuste do modelo matemático aos dados dos dois casos seria realizado com o emprego do programa livre $R$.

Os resultados obtidos neste trabalho não permitiram realizar o ajuste de curva da cinética de absorção (uma hipérbole retangular, similar à da cinética enzimática de Michaelis \& Menten). Neste caso, foi empregada apenas uma regressão linear do primeiro grau, considerando a análise de variância do delineamento experimental em blocos casualizados e o desdobramento dos tratamentos em regressão e falta de ajustamento. Todos os dados foram previamente submetidos aos testes de normalidade (ShaproWilk) e homogeneidade de variâncias (Fligner-Killeen) dos resíduos. As análises foram feitas no R.

\section{Método Kjeldahl para avaliação do teor de $\mathbf{N}$ total das raízes}

Este método é dividido em três etapas principais: a digestão, destilação e a titulação. A seguir será descrito o procedimento adotado pelo Laboratório que realizou as análises nas amostras de raiz.

Digestão: A amostra é digerida com ácido sulfúrico concentrado sob aquecimento, transformando todo o nitrogênio orgânico em íons amônio: a) Pesar 0,100 gr da amostra de material vegetal previamente preparada e transferir para o tubo digestor; b) Adicionar 1,5 gr de Sulfato de Potássio $\left(\mathrm{K}_{2} \mathrm{SO}_{4}\right)$. Adicionar 0,3 gr de Sulfato de Cobre (CuSO4) e em seguida adicionar $3 \mathrm{ml}$ de $\mathrm{H}_{2} \mathrm{SO}_{4}$ concentrado; c) Colocar no bloco digestor a $50^{\circ} \mathrm{C}$ e aumentar a temperatura lentamente até $350^{\circ} \mathrm{C}$, até a solução clarear e deixar mais 30 minutos; d) Deixar esfriar, adicionar $20 \mathrm{ml}$ de água destilada, agitar até dissolver o resíduo, que as vezes solidifica.

Destilação: a solução obtida é alcalinizada com hidróxido de sódio concentrado e a amônia produzida nessa etapa é destilada e captada por uma solução de ácido bórico, formando borato de amônio: a) Pipetar $10 \mathrm{ml}$ da solução de ácido bórico $\left(\mathrm{H}_{3} \mathrm{BO}_{3}\right)$, mais indicador e colocar em erlemayer de $125 \mathrm{ml}$; b) Encaixar o tubo de digestão no destilador e colocar o erlemayer na saíde deste último; c) Medir $10 \mathrm{ml}$ de Hidróxido de Sódio $(\mathrm{NaOH}) 13 \mathrm{~N}$, diretamente no copo de entrada do destilador e abrir a torneira, lentamente, para que a solução misture com o conteúdo do tubo de difestão. Lavar o copo de entrada com água destilada; d) Fechar as torneiras e elevar a temperatura do micro destilador até a marca 10. Quando iniciar a fervura voltar até a marca 6 ou 7 e manter esta temperatura; e) Deixar destilar até que a solução Ácido Bórico passe aproximadamente o dobro do volume inicial $(+-50 \mathrm{ml})$. 
Titulação: consiste na titulação do borato de amônio com uma solução de ácido sulfúrico ou de ácido clorídrico padronizada $(\mathrm{HCl})$ de título conhecido até a viragem do indicador: a) Titular com a amônia com ( $\mathrm{HCl})$ 0,07143 $\mathrm{N}$ até a mudança de cor verde para rosa escuro; b) Fazer prova em branco pesando $100 \mathrm{mg}$ de EDTA, passando por todo o processo de digestão, destilação e titulação.

Cálculo: Gasto de HCL 0,07143 N = \% N na amostra.

\section{RESULTADOS E DISCUSSÃO}

O método proposto neste trabalho não produziu resultados satisfatórios. Verificou-se que o teor de $\mathrm{N}$ total quantificado nas raízes das plantas foi praticamente igual para todas as plantas submetidas às diferentes concentrações de $\mathrm{NO}_{3}^{-}$na solução nutritiva. Em alguns casos, inclusive, o teor de $\mathrm{N}$ total no "branco", submetido a 0,0 $\mathrm{mM}$ de $\mathrm{NO}_{3}{ }^{-}$, foi superior ao de algumas plantas submetidas a maiores concentrações e, nesses casos, decidiu-se atribuir o valor nulo para o cálculo do influxo.

Na Figura 6 se observa o resultado da análise de regressão para os dados obtidos das amostras de raiz que foram submetidas às concentrações de nitrato dentro da faixa de ação dos transportadores de baixa afinidade e na Figura 7, de alta afinidade. De igual maneira, as análises de variâncias respectivas dessas duas etapas do experimento estão nas Tabelas 3 e 4.

Tabela 3: Análise de variância do influxo de nitrato referente ao sistema de baixa afinidade.

\begin{tabular}{llllll}
\hline Causa de variação & gl & SQ & MQ & F & p-valor \\
\hline Tratamentos & 9 & 0,42192 & 0,04688 & 1,24630 & 0,31471 \\
Regressão & 1 & 0,00278 & 0,00278 & 0,07388 & 0,78810 \\
Falta de ajuste & 8 & 0,41914 & 0,05239 & 1,39290 & 0,24956 \\
Blocos & 3 & 0,28661 & 0,095536 & 2,5399 & 0,08032 \\
Resíduo & 24 & 0,90274 & 0,03761 & & \\
Total & 36 & 1,61125 & & & \\
\hline
\end{tabular}

Teste de normalidade por Shapiro-Wilk: $\mathrm{W}=0,95281$; $\mathrm{p}$-valor $=0,1189$.

Teste de homogeneidade de variância por Fligner-Killeen: qui-quadrado = 8,247; df = 9; p-valor =0,5095.

Com esses resultados não é possível ajustar qualquer curva de cinética de absorção de nitrato, tanto para avaliar a atividade dos transportadores de alta quanto para baixa afinidade.

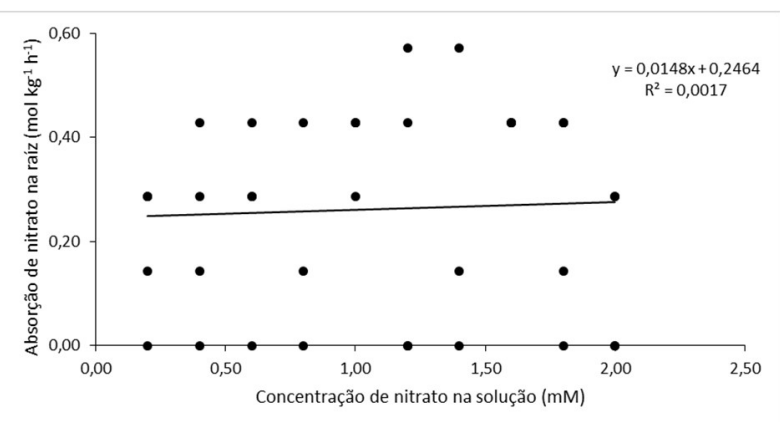

Figura 6: Gráfico da análise de regressão dos dados das amostras submetidas à concentrações de $0,0 \mathrm{mM}$ a 2,0 $\mathrm{mM}$ de nitrato.

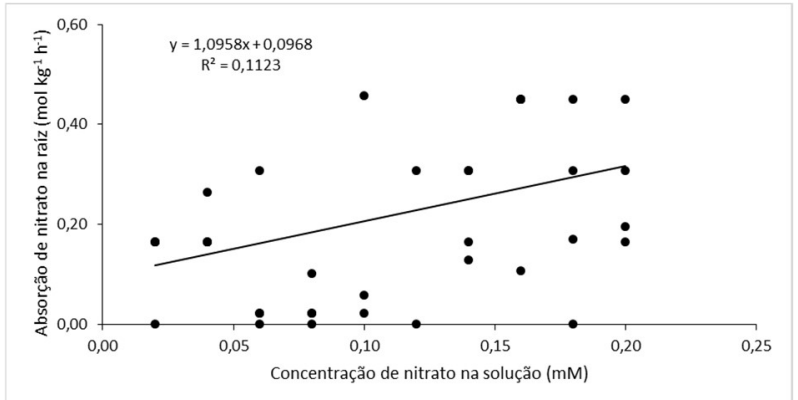

Figura 7: Gráfico da análise de regressão dos dados das amostras submetidas à concentrações de $0,0 \mathrm{mM}$ a 0,2 $\mathrm{mM}$ de nitrato.

As seguintes fontes de erro foram levantadas: (a) se a quantidade de nitrato absorvida pela raiz for menor ou igual ao valor referente à resolução do método de determinação do $\mathrm{N}$ total (Método Kjeldahl) no Laboratório de Análises de Plantas, isso significa dizer que não há como o influxo ser calculado utilizando esse 
método, (b) se a variabilidade natural do teor de $\mathrm{N}$ total (medido pelo método Kjeldahl) entre as repetições de um mesmo tratamento for superior à quantidade de nitrato absorvida pela raiz, isso inviabiliza o uso do método Kjeldahl na detecção de nitrato para fins de cinética enzimática e (C) se o tempo de permanência do nitrato na raiz antes de ser translocado para a parte aérea for menor do que o experimentalmente necessário para realizar os procedimentos amostrais, não será possível detectá-lo, impossibilitando calcular o influxo.

Tabela 4: Análise de variância do influxo de nitrato referente ao sistema de alta afinidade.

\begin{tabular}{llllll}
\hline Causa de variação & gl & SQ & MQ & F & p-valor \\
\hline Tratamentos & 9 & 0,42371 & 0,04708 & 1,26720 & 0,30040 \\
Regressão & 1 & 0,158375 & 0,158375 & 4,26302 & 0,04992 \\
Falta de ajuste & 8 & 0,26533 & 0,03317 & 0,89276 & 0,53744 \\
Blocos & 3 & 0,02024 & 0,00675 & 0,1816 & 0,9079 \\
Resíduo & 24 & 0,96592 & 0,03715 & & \\
Total & 38 & 1,409861 & & & \\
\hline
\end{tabular}

Teste de normalidade por Shapiro-Wilk: $W=0,96182$; $p$-valor = 0,205.

Teste de homogeneidade de variância por Fligner-Killeen: qui-quadrado =14,778; df = 9; p-valor =0,0972.

Analisando-se a primeira fonte de erro, em relação à resolução do método, ou em outras palavras o seu limite de detecção, a quantidade mínima de volume do titulante $(\mathrm{HCl}, 0,07143 \mathrm{~N})$ possível de ser dispensada e identificada pelo usuário na bureta é de 0,05 $\mathrm{mL}$. Isso significa dizer que, teoricamente, seria possível detectar até um mínimo de $50,0249 \mu \mathrm{g}$ ou 3,5715 $\mu \mathrm{mol}$ de $\mathrm{N}$ no titulado $\left(\mathrm{NH}_{4} \mathrm{H}_{2} \mathrm{BO}_{3}\right.$, considerando o seu mol igual a 1063,965 $\mathrm{g} \mathrm{mol}^{-1}$ ). Como são empregados $100 \mathrm{mg}$ de massa seca da raiz nesse procedimento, a concentração expressa em porcentagem de $\mathrm{N}$ avaliada seria de 0,05\% e expressa em número de moles, de $35,715 \mathrm{mmol} \mathrm{kg}^{-1} \mathrm{MS}$. Considerando do tempo de $30 \mathrm{~min}$ em que o processo do influxo de nitrato foi medido, é possível se chegar ao valor de influxo medido dessa forma igual a $71,43 \mathrm{mmol} \mathrm{h}^{-1} \mathrm{~kg}^{-1} \mathrm{MS}$. Neste caso improvável, porque do ponto de vista instrumental o processo de titulação se encerraria apenas com uma única gota dispensada da bureta, o valor de influxo obtido está totalmente aquém do requerimento exigido para a medição da cinética do influxo de nitrato pelos transportadores de baixa afinidade e muito menos ainda para os de alta afinidade. Por exemplo, Justino et al. (2006), avaliando os efeitos do Al sobre a absorção e redução de nitrato em duas cultivares nacionais de arroz, encontraram valores da velocidade máxima $\left(V_{\max }\right)$ de influxo variando de 19,41 a 23,34 $\mathrm{mmol} \mathrm{h}^{-1} \mathrm{~kg}^{-1} \mathrm{MS}$. São comuns valores de influxo de nitrato em raízes de plantas de arroz da ordem de 18,00 a $81,00 \mathrm{mmol} \mathrm{h}^{-1} \mathrm{~kg}^{-1} \mathrm{MS}$ (RAMAN et al., 1995) ou 5,4 a $68,4 \mathrm{mmol} \mathrm{h}^{-1} \mathrm{~kg}^{-}$ ${ }^{1}$ MS (YOUNGDAHL et al., 1982) e esses são valores que devem se encontrar dentro da faixa de detecção do método, não devendo estar tanto no seu limite máximo quanto mínimo de resolução.

Com relação à segunda fonte de erro, é possível observar nos Quadros 1 e 2 que as diferenças máximas encontradas nas concentrações de $\mathrm{N}$ total obtidas entre as repetições de um mesmo tratamento são inferiores às magnitudes das diferenças entre os valores de influxo de nitrato que se pretende avaliar entre dois níveis consecutivos dos tratamentos aplicados (concentrações de nitrato na solução nutritiva). Isso indica que a variabilidade natural do teor de $\mathrm{N}$ total presente nas raízes numa condição qualquer pode ser empregado na estimativa do influxo de nitrato desde que o método empregado nessa determinação tenha a resolução desejada. 
Quadro 1: Teores de $\mathrm{N}$ total das amostras avaliadas segundo os diferentes tratamentos aplicados para avaliação de influxo por transportadores de baixa afinidade.

\begin{tabular}{|c|c|c|c|}
\hline $\begin{array}{l}\text { Tratamentos (teor de } \mathrm{NO}_{3}{ }^{-} \text {na solução, } \\
\text { mol L-1) }\end{array}$ & Repetições & $\begin{array}{l}\text { Teor de } \mathrm{N} \text { total }(\mathrm{mmol} \mathrm{kg-} \\
\left.{ }^{1} \mathrm{MS}\right)\end{array}$ & $\begin{array}{l}\text { Máxima diferença entre as repetições (mmol } \\
\mathrm{kg}^{-1} \mathrm{MS} \text { ) }\end{array}$ \\
\hline \multirow{4}{*}{ ( } & 1 & 2,07 & \multirow{4}{*}{ C } \\
\hline & 2 & 1,93 & \\
\hline & 3 & 2,00 & \\
\hline & 4 & 2,00 & \\
\hline \multirow{4}{*}{0,20} & 1 & 2,14 & \multirow{4}{*}{0,21} \\
\hline & 2 & 1,93 & \\
\hline & 3 & 2,07 & \\
\hline & 4 & 2,14 & \\
\hline \multirow{4}{*}{0,40} & 1 & 1,93 & \multirow{4}{*}{0,29} \\
\hline & 2 & 2,07 & \\
\hline & 3 & 2,21 & \\
\hline & 4 & 2,14 & \\
\hline \multirow{4}{*}{0,60} & 1 & 2,14 & \multirow{4}{*}{0,29} \\
\hline & 2 & 2,21 & \\
\hline & 3 & 2,14 & \\
\hline & 4 & 1,93 & \\
\hline \multirow{4}{*}{0,80} & 1 & 1,93 & \multirow{4}{*}{0,29} \\
\hline & 2 & 2,07 & \\
\hline & 3 & 2,21 & \\
\hline & 4 & & \\
\hline \multirow{4}{*}{1,00} & 1 & 2,14 & \multirow{4}{*}{0,29} \\
\hline & 2 & 2,43 & \\
\hline & 3 & 2,21 & \\
\hline & 4 & 2,21 & \\
\hline \multirow{4}{*}{1,20} & 1 & 1,86 & \multirow{4}{*}{0,43} \\
\hline & 2 & 2,28 & \\
\hline & 3 & 2,00 & \\
\hline & 4 & 2,21 & \\
\hline \multirow{4}{*}{1,40} & 1 & 2,07 & \multirow{4}{*}{0,36} \\
\hline & 2 & 2,28 & \\
\hline & 3 & 1,93 & \\
\hline & 4 & & \\
\hline \multirow{4}{*}{1,60} & 1 & 2,21 & \multirow{3}{*}{0,00} \\
\hline & 2 & 2,21 & \\
\hline & 3 & 2,21 & \\
\hline & 4 & & \\
\hline \multirow{4}{*}{1,80} & 1 & 2,07 & \multirow{4}{*}{0,36} \\
\hline & 2 & 2,21 & \\
\hline & 3 & 2,21 & \\
\hline & 4 & 1,86 & \\
\hline \multirow{4}{*}{2,00} & 1 & 1,86 & \multirow{4}{*}{0,29} \\
\hline & 2 & 2,14 & \\
\hline & 3 & 2,14 & \\
\hline & 4 & 2,00 & \\
\hline
\end{tabular}

Quadro 2: Teores de $\mathrm{N}$ total das amostras avaliadas segundo os diferentes tratamentos aplicados para avaliação de influxo por transportadores de alta afinidade.

\begin{tabular}{|c|c|c|c|}
\hline $\begin{array}{l}\text { Tratamentos (teor de } \mathrm{NO}_{3}{ }^{-} \text {na solução, } \\
\text { mol L-1) }\end{array}$ & Repetições & $\begin{array}{l}\text { Teor de } \mathrm{N} \text { total }(\mathrm{mmol} \mathrm{kg-} \\
\left.{ }^{1} \mathrm{MS}\right)\end{array}$ & $\begin{array}{l}\text { Máxima diferença entre as repetições (mmol } \\
\mathrm{kg}^{-1} \mathrm{MS} \text { ) }\end{array}$ \\
\hline \multirow[t]{4}{*}{ ( } & 1 & 1,94 & \multirow[t]{4}{*}{ 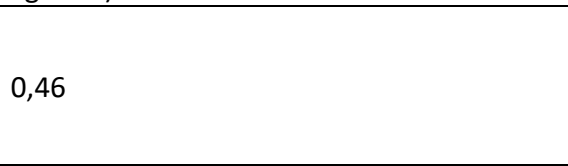 } \\
\hline & 2 & 2,07 & \\
\hline & 3 & 2,09 & \\
\hline & 4 & 1,86 & \\
\hline \multirow{4}{*}{0,02} & 1 & 2,07 & \multirow{4}{*}{0,29} \\
\hline & 2 & 1,93 & \\
\hline & 3 & 2,07 & \\
\hline & 4 & 2,07 & \\
\hline \multirow{3}{*}{0,04} & 1 & 2,07 & \multirow{3}{*}{0,10} \\
\hline & 2 & 2,07 & \\
\hline & 3 & 2,07 & \\
\hline
\end{tabular}




\begin{tabular}{|c|c|c|c|}
\hline & 4 & 2,12 & \\
\hline \multirow{4}{*}{0,06} & 1 & 2,00 & \multirow{4}{*}{0,34} \\
\hline & 2 & 1,97 & \\
\hline & 3 & 2,00 & \\
\hline & 4 & 2,14 & \\
\hline \multirow{4}{*}{0,08} & 1 & 2,00 & \multirow{4}{*}{0,18} \\
\hline & 2 & 2,04 & \\
\hline & 3 & 2,00 & \\
\hline & 4 & 1,86 & \\
\hline \multirow{4}{*}{0,10} & 1 & 2,00 & \multirow{4}{*}{0,39} \\
\hline & 2 & 2,22 & \\
\hline & 3 & 2,39 & \\
\hline & 4 & 2,02 & \\
\hline \multirow{4}{*}{0,12} & 1 & & \multirow{4}{*}{0,38} \\
\hline & 2 & 2,31 & \\
\hline & 3 & 1,93 & \\
\hline & 4 & 2,14 & \\
\hline \multirow{4}{*}{0,14} & 1 & 2,14 & \multirow{4}{*}{0,09} \\
\hline & 2 & 2,07 & \\
\hline & 3 & 2,14 & \\
\hline & 4 & 2,05 & \\
\hline \multirow{4}{*}{0,16} & 1 & 2,04 & \multirow{4}{*}{0,17} \\
\hline & 2 & 2,21 & \\
\hline & 3 & 2,21 & \\
\hline & 4 & 2,21 & \\
\hline \multirow{4}{*}{0,18} & 1 & 2,21 & \multirow{4}{*}{0,29} \\
\hline & 2 & 2,07 & \\
\hline & 3 & 1,93 & \\
\hline & 4 & 2,14 & \\
\hline \multirow{4}{*}{0,20} & 1 & 2,14 & \multirow{4}{*}{0,14} \\
\hline & 2 & 2,09 & \\
\hline & 3 & 2,07 & \\
\hline & 4 & 2,21 & \\
\hline
\end{tabular}

Observando os dados de influxo do nitrato em arroz em diferentes trabalhos publicados (RAMAN et al., 1995; YOUNGDAHL et al., 1982), é plausível considerar que os métodos capazes de diagnosticar valores de influxo da ordem de até $2,0 \mathrm{mmol} \mathrm{h}^{-1} \mathrm{~kg}^{-1} \mathrm{MS}$ são satisfatórios. Assim sendo, a magnitude da variabilidade do teor de $\mathrm{N}$ total entre as repetições de um mesmo tratamento de cinética de absorção de nitrato precisa ser inferior a esse valor. Pelos Quadros 1 e 2, considerando um tempo de 30 min de exposição das plantas aos tratamentos, para efeito de cálculos, tomando-se a maior diferença entre as repetições de um mesmo tratamento (Quadro 2, para o tratamento com 0,00 $\mathrm{mmol} \mathrm{L}^{-1}$ de nitrato, cujo valor da máxima diferença é igual a $0,46 \mathrm{mmol} \mathrm{kg}^{-1} \mathrm{MS}$ ), é possível verificar que nesse quesito, o método proposto neste trabalho é adequado, em se tratando de uso do $\mathrm{N}$ total das raízes para estimativa do influxo de nitrato.

A terceira fonte de erro pode ser eliminada em função das evidências de que sim, é possível detectar o influxo de nitrato em raízes de plantas jovens de arroz após 30 min de exposição das plantas aos diferentes tratamentos para estimativa da cinética de absorção, como pode ser visto nos trabalhos de Anti et al. (2001).

Outras fontes de erro não tão óbvias também podem ter afetado os resultados obtidos neste trabalho, contudo há necessidade de que sejam avaliadas com procedimentos experimentais capazes dessa avaliação.

O fato das plantas terem permanecido 72 horas em solução sem $\mathrm{N}$, pode ter ocasionado uma rápida absorção do N quando aplicados os tratamentos nas diferentes concentrações. Segundo Gazzarrini et al. 
(1999), a absorção de N aumenta quando plantas são submetidas a um período de deficiência do nutriente, sendo a magnitude desse incremento função da concentração de $\mathrm{N}$ na solução.

Um fator que deve ser levado em consideração é que o tempo de resposta dos genes que codificam as proteínas transportadoras, pode variar grandemente, resultando numa ampla variação de padrões de cinética de absorção.

Atualmente há grandes esforços da pesquisa voltados em aumentar a eficiência na utilização de nitrogênio pelas plantas, voltando-se principalmente aos estudos da eficiência das diferentes enzimas e suas isoformas envolvidas no ciclo do $\mathrm{N}$ na planta e à identificação dos transportadores de nitrogênio presentes na membrana plasmática das células. A manipulação dos transportadores de nitrato e amônio abre uma perspectiva de atuar-se de forma direta no processo de absorção de N pela planta. Para isso, são necessários o isolamento, a identificação, a caracterização e a clonagem dos genes responsáveis pela expressão dos transportadores de alta afinidade para $\mathrm{NO}_{3}{ }^{-}$e $\mathrm{NH}_{4}{ }^{+}$e transportadores de baixa afinidade para $\mathrm{NO}_{3}{ }^{-}$ (CRAWFORD, 1995; HUANG et al., 1996; TOURAINE et al., 1997; VON WIRÉN et al., 1997).

Um aspecto importante a ser considerado, no caso desse estudo, é que pode estar ocorrendo também a transição de um sistema de absorção para o outro, ou ainda, os dois sistemas poderiam estar atuando simultaneamente. Portanto investigações futuras devem ser conduzidas para caracterizar em quais faixas de concentração operam os sistemas de transporte de alta e baixa-afinidade de nitrato e de amônio em arroz.

\section{CONCLUSÕES}

O método proposto não produziu resultados satisfatórios, fundamentalmente devido à resolução (limite de detecção) do método utilizado na quantificação do teor de $\mathrm{N}$ total das raízes das plantas (método de Kjeldahl). Nesse sentido, seria interessante avaliar outros métodos, quer seja para detecção do $\mathrm{N}$ total, quer seja para a deteç̧ão exclusivamente do nitrato, mantendo o mesmo protocolo de avaliação do sistema radicular das plantas.

\section{REFERÊNCIAS}

ABADIE, T.; MAGALHÃES, J. R.. Construção de uma coleção nuclear de arroz para o Brasil. Pesquisa Agropecuária Brasileira, v.40, n.2, p.129-136, 2005. DOI: https://doi.org/10.1590/S0100-204X2005000200005

ABICHEQUER, D. A.. Morfologia e distribuição de raízes de arroz irrigado por inundação e sua relação com a absorção de nutrientes e rendimento de grãos. Tese (Doutorado em Ciência do Solo) - Universidade Federal do Rio Grande do Sul, Porto Alegre, 2004.

ANTI, A. B.; MORTATTI, J.; TRIVELIN, P. C. O.; BENDASSOLLI, J. A.. Radicular uptake kinetics of ${ }^{15} \mathrm{NO}_{3}{ }^{-}, \mathrm{CO}\left({ }^{15} \mathrm{NH}_{2}\right)_{2}$ and ${ }^{15} \mathrm{NH}_{4}{ }^{+}$in whole rice plants. Journal of Plant Nutrition, Athens, v.24, p.1695-1710, 2001.

ASLAM, M.; TRAVIS, R. L.; HUFFAKER, R. C.. Comparative kinetics and reciprocal inhibition of nitrate and nitrite uptake in roots of uninduced and induced barley (Hordeum vulgare L.) seedlings. Plant Physiology, v.99, p.1124-1133, 1992.

BARBER, S. A.. Soil nutrient bioavailability. New York: J. Wiley, 1984.

BECKER, L.; AMINPIROOZ, S.; HILLERT, B.; PEDIO, M.; HAASE, J.. Treefold-coordinated hollow adsorption site for $\mathrm{Ni}$ (111)c(4 X 2)- CO: A surface-extended x-ray-absorption finestructure study. Physical Review, v.47, n.15, p.9710-9714, 1993.

BREDEMEIER, C.; MUNDSTOCK, C. M.. Regulação da absorção e assimilação do nitrogênio nas plantas. Ciência Rural, v.30, p.365-372, 2000.

CAMPBELL, W. H.. Nitrate reductase structure, function and regulation: bridging de gap between biochemistry and 
physiology. Annual Review of Plant Physiology and Plant Molecular Biology, v.50, p.277-303, 1999.

CLASSEN, N.; BARBER, S. A.. A method for characterizing the relation between nutrient concentration and flux into roots of intact. Plant Physiology, Bethesda, v.54, n.4, p.564-568, 1974.

COUNCE, P. A.; KEISLING, T. C.; MITCHELL, A. J.. A uniform, objective, and adaptative system for expressing rice development. Crop Science, Madison, v.40, n.2, p.436-443, 2000.

CRAWFORD, N. M.. Nitrate: nutrient and signal for plant growth. The Plant Cell, Rockville, v.7, p.859-868, 1995.

EPSTEIN, E.; HAGAN, C. E.. A kinetic study of the absorption of alkali cations by barley roots. Plant Physiology, Bethesda, v.27, p.457-474, 1952.

FAGERIA, N. K.. Adubação e nutrição mineral da cultura do arroz. Rio de Janeiro: Campus; Goiânia: EMBRAPA-CNPAF, 1984.

FAGERIA, N. K.; BALIGAR, V. C.. Response of common bean, upland rice, corn, wheat, and soybean to soil fertility of an Oxisol. Journal of Plant Nutrition, New York, v.20, n.10, p.1279-1289, 1997.

FAGERIA, N. K.; BALIGAR, V. C.. Yield and yield componentes of lowland rice as influenced by timing of nitrogen fertilization. Journal of Plant Nutrition, New York, v.22, n.1, p.23-32, 1999.

FAGERIA, N. K.; BALIGAR, V. C.. Lowland rice response to nitrogen fertilization. Communication in Soil Science and Plant Analysis, New York, v.32, n.9-10, p.1405-1429, 2001.

FAGERIA, N. K.; SLATON, N. A.; BALIGAR, V. C.. Nutrient management for improving lowland rice productivity and sustainability. Advances in Agronomy, New York, v.80, p.63152, 2003.

FAGERIA, N. K.; STONE, L. F.; SANTOS, A. B.. Manejo da fertilidade do solo para arroz irrigado. Santo Antônio de Goiás: Embrapa Arroz e Feijão, 2003.

FONSECA, J. R.; RODRIGUES, A.; GUSMÃO, E.. Descritores botânicos, agronômicos e fenológicos do Arroz (Oryza sativa L.). Embrapa Arroz e Feijão, 2008.

FORDE, B. G.. Nitrate transporters in plants: structure, function and regulation. Biochimica et Biophysica Acta, v.1465, p.219-235, 2000.

FORDE, B. G.. Local and long-rang signalling pathways regulating plant responses to nitrate. Annual Review of Plant Biology, Palo Alto, v.53, n.1, p.203-224, 2002.

GAZZARRINI, S.; LEJAY, L.; GOJON, A.; NINNEMANN, O.; FROMMER, W. B.; VONWIREN, N.. Three functional transporters for constitutive, diurnally regulated, and starvationinduced uptake of ammonium into Arabidopsis roots. Plant Cell, v.11, p.937-947, 1999.

GLASS, A. D. M.; SHAFF, J. E.; KOCHIAN, L. V.. Studies of the uptake of nitrate in barley.4.Electrophysiology. Plant
Physiology, Rockville, v.99, n.2, p.456-463, 1992.

GLASS, A. D. M.; BRITTO, D. T.; KAISER, B. N.; KINGHORN, J. R.; KRONZUCKER, H. J.; KUMAR, A.; OKAMOTO, M.; RAWAT, S.; SIDDIQI, M. Y.; UNKLES, S. E.; VIDMAR, J. J.. The regulation of nitrate and ammonium transport system in plants. Journal of Experimental Botany, v.53, p.855-864, 2002.

GREENLAND, D. J.. Nitrate fluctuations in tropical soils. Journal Agricultural Science, Tokyo, v.50, p.82-91, 1958.

HORN, D.; ERNANI, R. P.; SANGOI, L.; SCHWEITZER, C.; CASSOL, C. P.. Parâmetros cinéticos e morfológicos da absorção de nutrientes em cultivares de milho com variabilidade genética contrastante. Revista Brasileira de Ciência do Solo, Viçosa, v.30, n.1, 2006.

HUANG, N.; CHIANG, C.; CRAWFORD, N. M.; TSAY, Y. F.. CHL1 encodes a component of the low-affinity nitrate uptake system in Arabidopsis and shows cell type-specific expression in roots. The Plant Cell, Rockville, v.8, p.21832191, 1996. DOI: https://doi.org/10.1105/tpc.8.12.2183

JUSTINO, G. C.; CAMBRAIA, J.; OLIVA, M. A.; OLIVEIRA, J. A.. Absorção e redução de nitrato em duas cultivares de arroz na presença de alumínio. Revista Pesquisa Agropecuéria Brasileira, v.41, n.8, p.1285-1290, 2006.

KAISER, W. M.; HUBER, S. C.. Regulation of nitrate reductase: mechanism, physiological relevance and environmental triggers. J. Exp. Bot., v.52, p.1981-1989, 2001.

KRONZUCKER, H. J.; SIDDIQI, M. Y.; GLASS, A. D. M.. Kinetics of $\mathrm{NO}_{3}$ - influx in spruce. Plant Physiology, v.109, p.319-326, 1995.

KHUSH, G. S.. Aumento do potencial genético de rendimento do arroz: perspectivas e métodos. In: Arroz na América Latina: perspectivas para o incremento da produção e do potencial produtivo. Goiânia: EMBRAPA-CNPAF-APA, 1995. p.13-29.

LEA, P. J.; AZEVEDO, R. A.. Nitrogen use efficiency. Uptake of nitrogen from the soil. Annals of Applied Biology, v.149, n.3, p.243-247, 2006.

LI, B. Z.; MERRICK, M.; LI, S.-M.; LI, H.-Y.; ZHU, S.-W.; SHI, W.M.; SU, Y.-H.. Molecular Basis and Regulation of Ammonium Transporter in Rice. Rice Science, Pequim, v.16, n.4, p.314322, 2009. DOI: https://doi.org/10.1016/S16726308(08)60096-7

LI, H.; HU, B.; CHU, C.. Nitrogen use efficiency in crops: lessons from Arabidopsis and rice. Journal of Experimental Botany, v.68, p.2477-2488, 2017.

MOKHELE, B.; ZHAN, X.; YANG, G.; ZHANG, X.. Review: nitrogen assimilation in crop plants and its affecting factors. Canadian Journal of Plant Science, v.92, n.3, p.399-405, 2012.

MORAIS, O. P.; CASTRO, E. M.; SOUZA, N. R. G.; PRABHU, A. S.; BASSINELLO, P. Z.; FONSECA, J. R.. Cultivares de Arroz de Terras Altas para o Mato Grosso. Circular Técnica 68. EMBRAPA, 2004. 
NARDOTO, G. B.; BUSTAMANTE, M. C.. Effects of fire on soil nitrogen dynamics and microbial biomass in savannas of Central Brazil. Pesquisa Agropecuária Brasileira, Brasília, v.38, n.8, p.955-962, 2003.

OLIVIERA, G. P.. Atributos genéticos, morfofisiológicos e agronômicos de subamostras de arroz e feijão do Pantanal Mato-grossense. Tese (Doutorado em Agricultura Tropical) Universidade Federal de Mato Grosso, Cuiabá, 2017.

PURCINO, A. A. C.; MAGNAVACA, R.; MACHADO, A. T.; MARRIEL, I. E.. Atividade da redutase do nitrato em genótipos antigos e modernos de milho, cultivados sob dois níveis de nitrogênio. Revista Brasileira de Fisiologia Vegetal, Campinas, v.6, n.1, p.41-46, 1994.

RAMAN, D. R.; SPANSWICK, R. M.; WALKER, L. P.. The kinetic of nitrate uptake from flowing solutions by rice: influence of pretreatment and light. Bioresource Technology, v.53, p.125-132, 1995.

RUIZ, H. A.. Estimativas dos parâmetros cinéticos em Km e Vmáx por uma aproximação gráfico-matemática. Revista Ceres, Viçosa, v.32, n.179, p.79-84, 1985.

RUIZ, H. A.; FERNANDES FILHO, E. I.. Cinética: software para estimar as constantes Vmáx e Km da equação de MichaelisMenten. In: REUNIÃO BRASILEIRA DE FERTILIDADE DO SOLO E NUTRIÇÃO DE PLANTAS, 20. Anais. Campinas: Fundação Cargill, 1992. p.124-125.

SANTOS, A. B.; STONE, L. F.; VIEIRA, N. R. A.. A cultura do arroz no Brasil. 2 ed. Santo Antônio de Goiás: Embrapa Arroz e Feijão, 2006.

SEBER, G. A. F.; WILD, C. J.. Nonlinear Regression. Hobboken: Willey Interscience, 2003.

SOUZA, S. R.. Efeito da Aplicação Foliar de Nitrogênio PósAntese Sobre as Enzimas de Assimilação de $\mathrm{N}$ e Acúmulo de Proteína em Grãos de Arroz. Tese (Doutorado em Agronomia) - Universidade Federal Rural do Rio de Janeiro, Seropédica, Rio de Janeiro, 1995.

SOUZA, S. R.; STARK, E. M. L. M.; FERNANDES, M. S. Nitrogen remobilization during the reproductive period in two Brazilian rice varieties. Journal of Plant Nutrition, v.21, n.10, p.2049-2063, 1998.
SOUZA, S. R.; FERNANDES, M. S.. Nitrogênio. In: FERNANDES, M.. Nutrição Mineral de Plantas. Viçosa: SBCS, 2006. p.215252.

SOUZA, M. V.. Parâmetros cinéticos da absorção de amônio e expressão gênica dos transportadores OsAMT1 em variedades de arroz (Oryza sativa L.). Dissertação (Mestrado em Ciências) - Universidade Rural do Rio de Janeiro, Seropédica, 2010.

SUENAGA, A.; MORIYA, K.; SONODA, Y.; IKEDA, A.; VON WIRÉN, N.; HAYAKAWA, T.; YAMAGUCHI, J.; YAMAYA, T. Constitutive expression of a novel-type ammonium transporter OSAMT2 in rice plants. Plant Cell Physiology, Oxford, v.44, n.2, p.206-211, 2003. DOI: https://doi.org/10.1093/pcp/pcg017

TAIZ, L.; ZEIGER, E.; MOLLER, M. I.; MURPHY, A.. Fisiologia e Desenvolvimento Vegetal. 6 ed. Porto Alegre: Artmed, 2017.

TISCHNER, R.. Nitrate uptake and reduction in higher and lower plants. Plant, Cell and Environment., v.23, p.10051024, 2000.

TOURAINE, B.; GLASS, A. D. M.. $\mathrm{NO}_{3}{ }^{-}$and $\mathrm{ClO}_{3}{ }^{-}$fluxes in the chl 1-5 mutant of Arabidopsis thaliana. Plant Physiology, Lancaster, v.114, p.137-144, 1997.

VON WIRÉN, N.; GAZZARRINI, S.; FROMMER, W. B.. Regulation of mineral nitrogen uptake in plants. Plant and Soil, The Hague, v.196, p.191-199, 1997.

WETSELAAR, R.. Nitrate distribution in tropical soils. I. Possible cause of nitrate accumulation near the surface after a long dry period. Plant and Soil, Dordrecht, v.15, p.110-120, 1961a.

WETSELAAR, R.. Nitrate distribution in tropical soils. II. Extent of capillary accumulation of nitrate during a long dry period. Plant and Soil, Dordrecht, v.15, p.121-133, 1961b.

YOSHIDA, S.. Fundamentals of rice crop Science. Manila: The International Rice Research Institute, 1981.

YOUNGDAHL, L. J.; PACHECO, R.; STREET, J. J.; VLEK, P. L. G.. The kinetics of ammonium and nitrate uptake by young rice plants. Plant and Soil, v.69, p.225-232, 1982.

A CBPC - Companhia Brasileira de Produção Científica (CNPJ: 11.221.422/0001-03) detém os direitos materiais desta publicação. Os direitos referem-se à publicação do trabalho em qualquer parte do mundo, incluindo os direitos às renovações, expansões e disseminações da contribuiç̃o, bem como outros direitos subsidiários. Todos os trabalhos publicados eletronicamente poderão posteriormente ser publicados em coletâneas impressas sob coordenação da Sustenere Publishing, da Companhia Brasileira de Produção Científica e seus parceiros autorizados. Os (as) autores (as) preservam os direitos autorais, mas não têm permissão para a publicação da contribuição em outro meio, impresso ou digital, em português ou em tradução. 